D.O.I.: $10.3895 / \mathrm{S} 1808-04482010000100009$

\title{
MELHORIA DE UM PROCESSO PRODUTIVO UTILIZANDO COMO REFERÊNCIA UM MODELO DO PROCESSO CRIATIVO NA SOLUÇÃO
}

\section{IMPROVEMENT OF A PRODUCTIVE PROCESS UTILIZING AS REFERENCE A MODEL OF THE CREATIVE PROCESS FOR SOLUTION}

\author{
Alexandre de Castro Alves ${ }^{1}$; Aldo Braghini Júnior ${ }^{2}$ \\ ${ }^{1}$ Universidade Tecnológica Federal do Paraná - UTFPR - Ponta Grossa - Brasil \\ alexandrealves@utfpr.edu.br \\ ${ }^{2}$ Universidade Tecnológica Federal do Paraná - UTFPR - Ponta Grossa - Brasil \\ aldo@utfpr.edu.br
}

\begin{abstract}
Resumo
Na melhoria de processos produtivos costuma-se utilizar de ferramentas, técnicas ou métodos para o processo criativo que são na sua maioria sequenciais, como caminhos pré-definidos para a criação de ideias, conceitos e soluções com potencial inovador, em contraponto a ideias puramente técnicas. Entretanto, estes tipos de modelos e ferramentas limitam o processo criativo, bem como a sua aleatoriedade e temporalidade. Na busca por soluções criativas que não ocorram somente ao acaso, mas que contemplem a análise das variáveis estimuladoras de um processo criativo, bem como seu processo de criação, de forma atemporal e aleatória, realizou-se um estudo de caso com o Modelo Trevo Fractal. Neste trabalho contempla-se a eliminação ou a minimização dos problemas de qualidade do processo produtivo de uma indústria de médio porte, que atua no ramo farmacêutico, na região metropolitana de Curitiba. Busca-se estabelecer o rastreamento dos processos da empresa e suas variáveis, por meio da sua descrição, identificando-se competências, conhecimentos e ferramentas utilizadas nas ações, para se criar ideias, conceitos e uma solução criativa. A solução desenvolvida utiliza-se como referência o Modelo Trevo Fractal do processo criativo e que após ter sido implantada, apresenta como resultado a eliminação do principal problema produtivo (53,8\% do total) e a diminuição do segundo maior problema (de 12,5\% para 0,5\%. O tempo necessário para a criação, o desenvolvimento e a implantação da solução criativa foi de três meses, o que potencializou uma rápida melhoria do processo produtivo, sendo que nesse processo não foram necessárias alterações ou aquisições em equipamentos produtivos.
\end{abstract}

Palavras-chave: melhoria de processo produtivo; modelo do processo criativo; soluções criativas.

\section{Introdução}

Para a gestão dos negócios atuais necessita-se de novas soluções e maneiras de se pensar, enfrentando-se as rápidas mudanças dos mesmos, e na área industrial não seria diferente, deve-se resolver os problemas que devem ser transformados em oportunidades. As empresas precisam ser 
mais competitivas e a criatividade torna-se uma ferramenta importante nesse caminho, influindo das estratégias a melhoria dos produtos e processos produtivos, para o desenvolvimento de produtos.

No entanto, os processos de criatividade seguem desenvolvimentos aleatórios e as indústrias necessitam de modelos que ofereçam suporte descritivo das ações, ligadas e organizadas no tempo, fornecendo um resultado mensurável. Sendo que, os modelos do processo criativo costumam ser sequenciais e não expressam o fator temporalidade, limitando-se muitas vezes à utilização de métodos e ferramentas de apoio à solução criativa de problemas ou estímulo a geração de ideias.

O Modelo Trevo Fractal (MTF) do processo criativo aplicado a um processo produtivo, objeto desse trabalho, segundo Alberti (2006a), descreve mais precisamente o processo da criatividade, sendo um modelo aleatório, atemporal e não limitado. Esse modelo permite estabelecer o rastreamento e a descrição desse processo na empresa, identificando competências, conhecimentos, ferramentas e os métodos ligados às ações, confrontando-se as informações.

Este trabalho apresenta a aplicação desse modelo de criatividade em uma indústria farmacêutica de médio porte, como solução criativa para a resolução dos principais problemas de retrabalho da produção. A empresa pesquisada situa-se na região Metropolitana de Curitiba no estado do Paraná. Adotou-se o estudo de caso e a pesquisa exploratória (YIN, 2005), investigandose a aplicação do Modelo Trevo Fractal e suas variáveis, por meio de pesquisa qualitativa, por entrevistas e observações diretas, incluindo análise documental das atas das reuniões.

\section{Soluções criativas}

As empresas cada vez mais devem buscar melhorar seus processos produtivos, reduzindo-se custos e aumentando-se a qualidade dos processos e produtos, busca-se as inovações e o aumento da competitividade, por meio de soluções criativas. No entanto, as empresas necessitam de ferramentas, técnicas e métodos criativos que possibilitem soluções originais e eficazes.

Nesse caminho, Campbell (1960), De Bono (1968) e Simonton (1988) analisam o processo de criação através de estimulações randômicas, não controláveis e casuais, onde o mérito se encontra na interpretação do processo de seleção das ideias como soluções. Para Alencar (1996) esse processo criativo está associado aos processos de pensamento, tais como: intuição, insight, inspiração, iluminação, invenção e originalidade.

Dessa forma, com base nesses processos de pensamento e na busca por soluções criativas para os problemas potencializa-se a criação das ideias, sendo que, as empresas aplicam ferramentas, técnicas e métodos para se gerar essas ideias e as possíveis soluções. Utilizam-se nesses processos de criação das ideias e as soluções, entre outras, as seguintes ferramentas e métodos: Morphological Method (ZWICKY, 1948 e ROZENFELD, 2006); Brainstorming (OSBORN, 1953); Synectics 
(GORDON, 1961 e PRINCE, 1972); Lateral Thinking (DE BONO, 1968); Brainwriting - Method 635 (ROHRBACH, 1969); Value Analysis (MILES, 1972 e BASSO, 1991); Galeriemethod (HELLFRITZ, 1978); TRIZ (Theory of Inventive Problem Solving - ALTSHULLER, 1984); Mind Map (BUZAN, 1991); MESCRAI (Modifique, Elimine, Substitua, Combine, Rearrange, Adapte e Inverta - BAXTER, 1998).

No presente trabalho utiliza-se na modelagem do processo criativo em especial a Análise de Valor (Value Analysis), que segundo Miles (1972), apesar de possuir uma visão técnica, apresenta como uma técnica que possibilita um enfoque criativo e organizado, objetivando soluções, mediante um conjunto específico de técnicas e um grupo de pessoas.

Para Abramczuk (1991) a Análise de Valor possibilita a identificação das funções e custos desnecessários de um produto ou processo, para a sua melhoria. Para Back (1983) possibilita-se através do desdobramento funcional a transformação das funções em operações básicas, para análise, sem a redução de sua complexidade.

Para Basso (1991) ocorrem três etapas distintas na Análise de Valor: estabelecimento das funções, avaliação da função por comparação e desenvolvimento de alternativas para o valor. Sendo que o estabelecimento dessas funções se tornam necessárias para a sua utilização em classes específicas: Classe funcional (relacionada ao desempenho), Classe estética (relacionada à vendabilidade) e Classe de troca (soma das anteriores).

Essa identificação e implantação de novas ideias como soluções para as funções do produto e do processo produtivo possibilitam a criação da inovação, não sendo necessariamente uma invenção, viabiliza-se comercialmente uma ideia, como solução prática. Para tanto se requer mais que criatividade e solução intuitiva, necessita-se de criatividade administrativa para dar sequência na implantação das soluções (KANTER; KAO; WIERSEMA, 1998).

Para Alberti (2006a) pode-se subdividir a criatividade em dois tipos: a Criatividade Parametrizada (CP), intrínseca ao processo de concepção e que se influencia pelos parâmetros organizacionais das empresas e seu contexto tecnológico, e a Criatividade Funcional (CF), que se utiliza das funções técnicas ou de utilização.

Neste estudo pesquisou-se o processo criativo e suas soluções, através da análise e estímulo das variáveis da CF e CP do processso criativo do MTF, utilizando-se nesse processo de ferramentas para a transformação de ideias em soluções, em especial a Análise de Valor através da Análise Funcional. Dessa forma possibilita-se as identificações das funções do processo produtivo e a determinação dos principais conceitos de pesquisa das soluções e suas ideias, fundamental a evolução das mesmas no modelo do processo criativo Trevo Fractal. 


\section{Processo criativo}

Para análise das soluções torna-se necessário compreender as noções abordadas nos processos crativos, antes de se detalhar os conceitos definidos pelos pesquisadores e que se encontram incluídos no modelo do processo criativo Trevo Fractal (Alberti, 2006a). Por exemplo, o termo concepção torna-se o primeiro sinônimo de criação para alguns pesquisadores. No entanto, para Evbuomwan, Sivaloganathan e Jebb (1996) os processos de concepção se compõem de ações:

- De formulação de uma problemática;

- Baseadas em ferramentas;

- Baseadas na imaginação;

- Incrementais e evolutivas de uma ideia;

- Iterativas em seu processo;

- Lógicas e com critérios mensuráveis;

- Para a tomada de decisão;

- Em função das oportunidades.

Para os autores essas caracterizações mostram que a concepção não possui uma forma única, uniforme e intangível, mas que, em função do ambiente e do contexto pode desenvolver formas particulares de ações. Dessa forma a concepção utiliza das aptidões do ser humano em se adaptar as situações, devido às suas funções mentais, tendo como objetivo o conhecimento conceitual e racional. Conceber torna-se um ato intelectual de elaboração de uma ideia, sendo que a proposição de um produto ou processo se torna também um ato de compreensão de um conceito, de uma situação, para a criação da ideia que potencializa uma solução.

A conceituação do processo criativo se apresenta como sendo um processo recente, por ser abstrato e de difícil definição, embora as ideias mostram-se tão antigas quanto o homem. Para a excução desse processo criativo necessita-se mais que intuição, lampejos de criação e ideias fantásticas, nas empresas exige-se preparo e métodos para a resolução das situações do dia a dia, envolvendo investigação, análise e verificação das variáveis envolvidas, entre outras. Um dos primeiros modelos do processo criativo atribuiu-se ao psicólogo Graham Wallas (WALLAS, 1926) que o define como sendo um processo subconsciente do pensamento em quatro etapas sequenciais: 


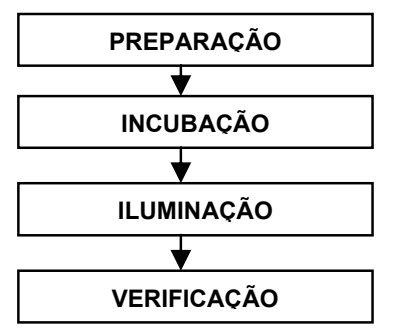

Fonte: Adaptado de Wallas (1926)

a) Preparação - Obtenção das informações relacionadas com o problema;

b) Incubação - Processo de trabalho inconsciente na busca da resolução do problema;

c) Iluminação - Após longo processo de incubação acontece a iluminação repentinamente;

d) Verificação - Concretiza-se a ideia e testa-se a sua aplicação e viabilidade.

Esse modelo de Wallas (1926) consiste num processo criativo simplificado, essencial ao desenvolvimento da sucessão criativa ligada a objetos industriais bem específicos. Na evolução desse modelo do processo criativo Rossman (1931) e Osborn (1953) incluem um equilíbrio sutil entre análise e imaginação, transparecendo o conceito de solução objetiva, descrevendo o modelo desse processo em sete fases sequenciais.

No entanto, Plsek (1997) propõe uma síntese dos modelos criativos em uma sequência circular iterativa, com repetição das fases, considerando-se em cada giro ou iteração uma nova entrada de dados e um novo dado de saída do processo criativo. Nesse modelo em cada giro alterase o processo de criação e seu resultado final, como segue:

Figura 2 - Modelo sequencial circular do processo criativo

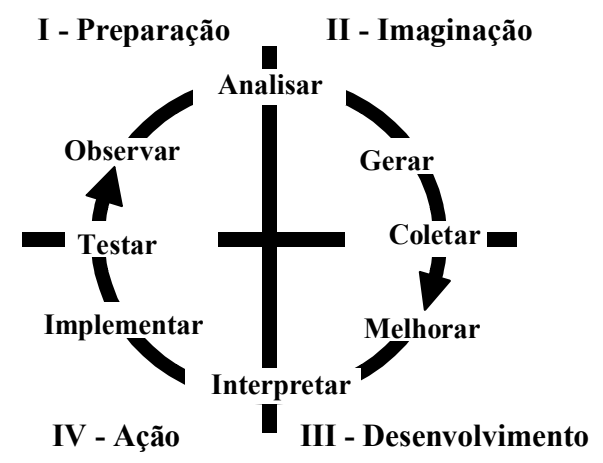

Fonte: Adaptado de Plsek (1997)

No entanto, os modelos sequenciais de criatividade na visão de Parnes (1992) e Treffinger, Iaksen e Dorval (1994) apresentam também uma abordagem combinatória, de técnicas analíticas e 
criatividade dirigida, permitindo-se a utilização de ferramentas de criatividade conhecidas e que foram popularizadas pelo modelo CPS (Creative Problem Solving).

Para Brennan e Dooley (2005) essa criatividade se encontra ligada a sete domínios que a influenciam o processo de criação, combinando-se a criatividade com: a gestão do conhecimento; a estrutura conceitual; a personalidade; a motivação; a cultura organizacional; a educação e o estilo de aprendizado.

Esses modelos do processo criativo propõem abordagens sequenciais que em geral começam com um questionamento, mas não expressam as atividades ligadas e organizadas no tempo, bem como, não podem ser objetivamente instrumentadas.

Para Alberti (2006a) esses domínios e as etapas não se tornam explícitas, como nas etapas Incubação e IIuminação de Wallas, as quais dependem da inteligência pessoal, mostrando que o processo mental, em parte subconsciente, não pode ser dirigido. Para o autor existem etapas de divergência e de convergência mais abrangentes no processo criativo, os quais envolvem os domínios e a interação dos dados, com processos mentais, sendo essa abordagem representada graficamente de forma sequencial como segue.

Figura 3 - Divergência e convergência no processo criativo baseado no modelo de Wallas

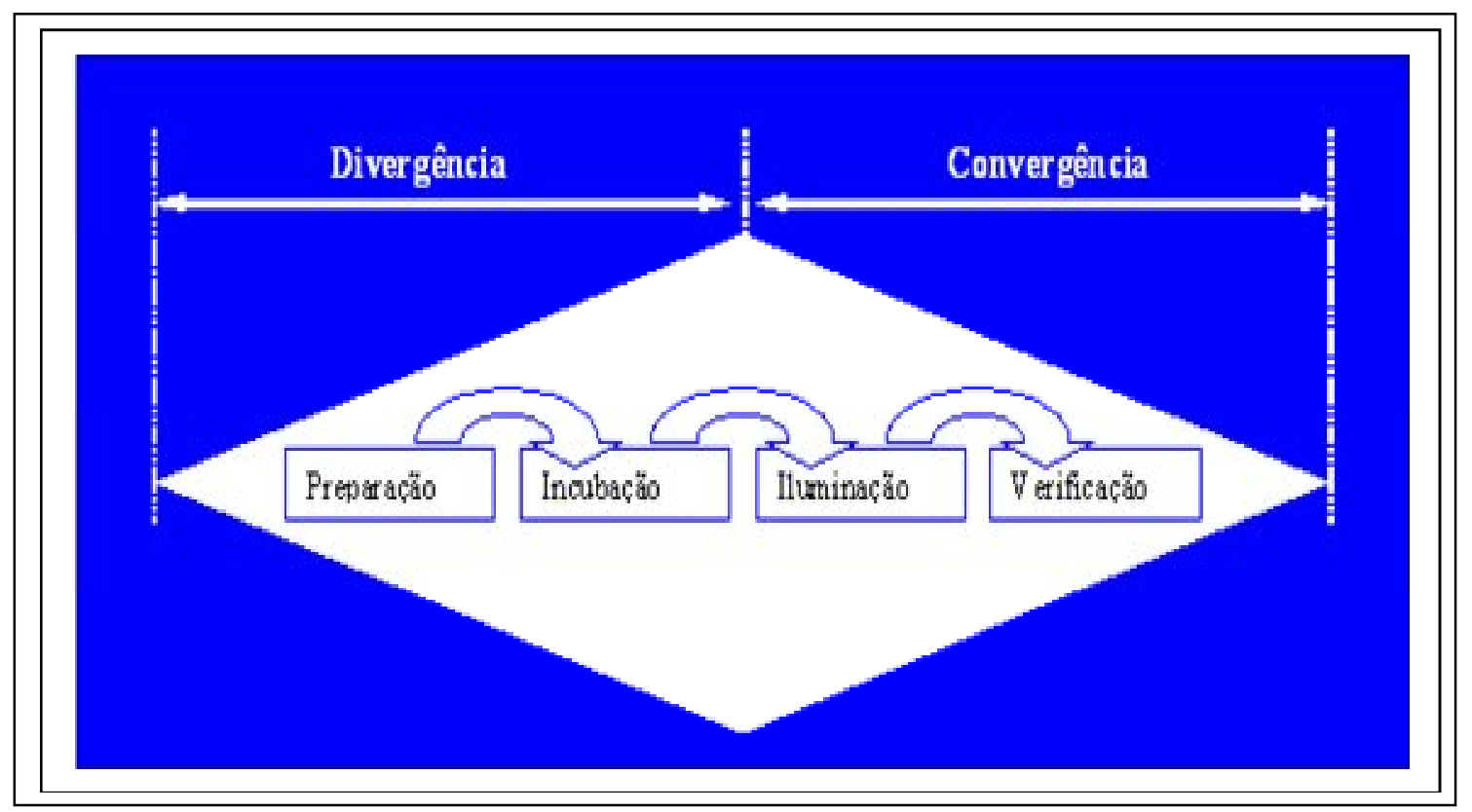

Fonte : Alberti (2006a)

Nesse processo de divergência e convergência permite-se elaborar novos serviços a serem prestados e novas funcionalidades aos produtos e processos, o que engloba um ambiente amplo e multidisciplinar, estimulado pela CF e também pela CP para cada empresa. Dessa forma nas empresas existem restrições tecnológicas limitantes ao processo de concepção dos produtos e processos, os quais devem ser estimulados pela convergência da CP. 
No entanto, na CF tratam-se os problemas de forma geral e desmaterializado, no sentido de se expressar as necessidades das funções dos produtos, isentas de tecnologia. Portanto, considera-se que a CF se torna uma atividade anterior à concepção, cujas restrições são ilimitadas e que pode ser o acionador da criação.

Essas variáveis do processo criativo devem fazer parte das metodologias para o desenvolvimento de produtos ou processo, pois estão diretamente ligadas ao mesmo, de forma intriseca. Para tanto, segundo Kanter, Kao e Wiersema (1998) nesses desenvolvimentos se requer mais que criatividade e solução intuitiva, necessita-se de criatividade administrativa para dar sequência às soluções geradas.

Necessita-se para a concepção e um processo criativo de um fluxo de ações que são estimuladas pelas variáveis industriais, administrativas e comerciais, transformando ideias em produtos e seus processos. Nesse sentido o MTF possibilita o suporte administrativo das ações e a aleatoriedade do processo criativo, com a utilização da $\mathrm{CF}$ em conjunto com a $\mathrm{CP}$, estimulando-se o processo de divergência e convergência, para a criação da solução.

\section{Modelo do processo criativo trevo fractal}

O MTF possui uma representação gráfica que descreve mais precisamente o processo aleatório da criatividade e suas variáveis, segundo Alberti (2006a), sendo construído para se atender a uma problemática de estimulação da criatividade e para a organização posterior desse processo. Para tanto, o Professor Alberti Pascal, durante seu doutorado na Ecole Centrale Paris (ALBERTI, 2006b) realizou pesquisas e entrevistas junto aos setores de Pesquisa e Desenvolvimento (P\&D) de fabricantes franceses de equipamentos automobilísticos, propondo-se o MTF após análises.

Pode-se iniciar o MTF por qualquer ação do modelo, sendo o caminho desse proceso aleatório, representando-se as ações subconscientes por meio de setas que ligam as ações e metaações, tais como: a formação das ideias, a confrontação cerebral das informações, a maturação do projeto em curso, etc (ALBERTI, 2006a). Não se impõe ponto de partida, se possibilita uma interação aleatória, sequencial ou simultânea, entre as ações do modelo, o qual possui três metasações que se subdividem em verbos de ação, para representação de cada ação, como mostrado: 


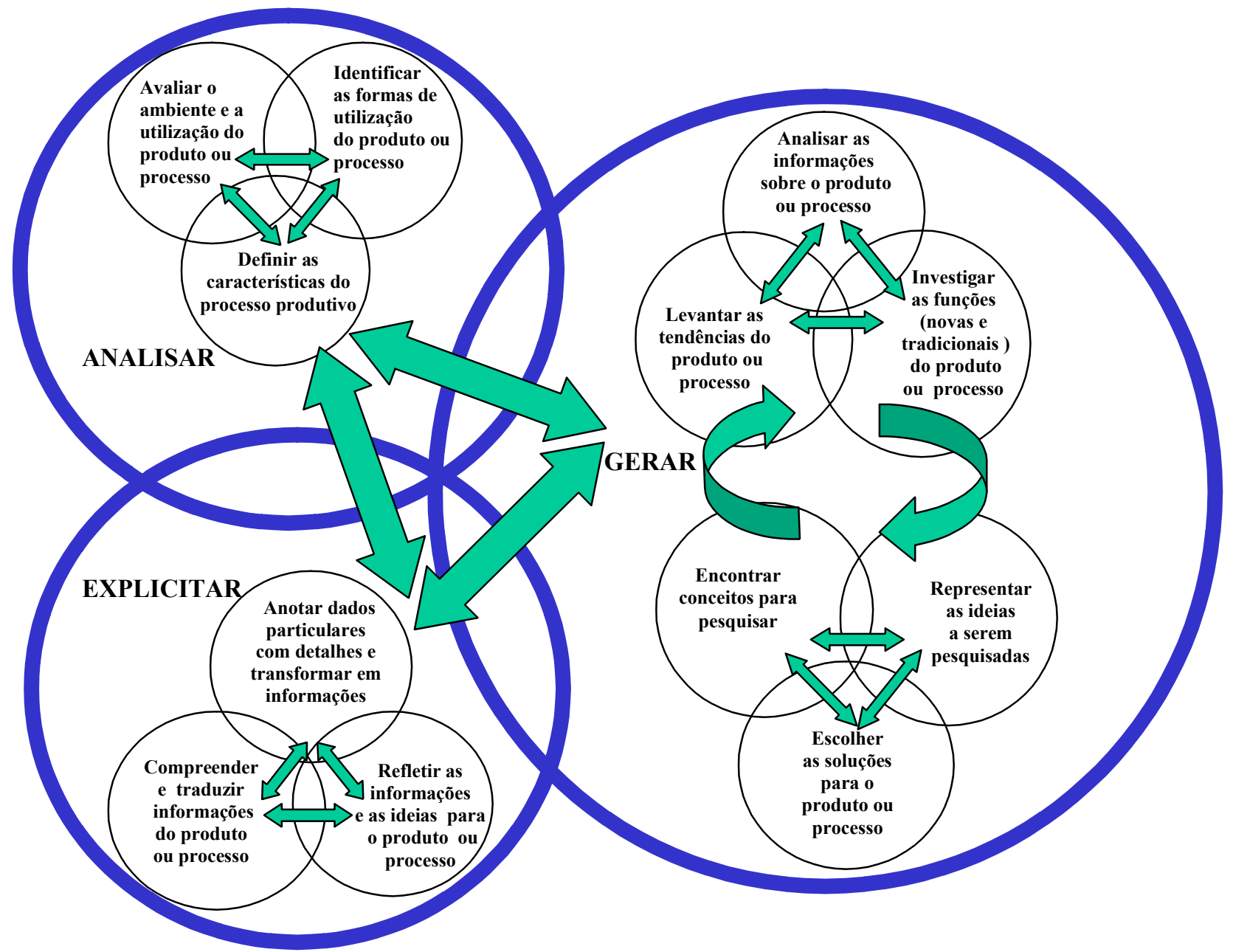

Fonte: Adaptado de Alberti (2006a)

\section{ANALISAR (Meta-ação)}

a) Ação - Avaliar o ambiente e a utilização do produto ou processo - busca exaustiva das necessidades, conceitos e informações do ambiente interno e externo, influenciando diretamente ou indiretamente no contexto de utilização do produto ou processo.

b) Ação - Identificar as formas de utilização do produto ou processo - definir as funções, serviços e as características do produto ou processo, essenciais a sua utilização, através das expectativas dos usuários e das restrições impostas pela sua utilização.

c) Ação - Definir as características do processo produtivo - definir quais as características do processo produtivo e suas funções, proporcionando a análise das etapas. 


\section{GERAR (Meta-ação)}

d) Ação - Analisar as informações sobre o produto ou processo - visa analisar a concorrência, as informações dos produtos ou processos, os produtos ou processos equivalentes, os materiais, detalhes de normas, regulamentos, etc.

e) Ação - Levantar as tendências do produto ou processo - levantar e analisar os conceitos dos produtos ou processos disponíveis no mercado e compreender os modos dos usuários na utilização desses conceitos, projetando as tendências do produto ou processo.

f) Ação - Investigar as funções (novas e tradicionais) do produto ou processo - expressar através de problemáticas de utilização (contextualização das necessidades de utilização) os serviços e funções do produto ou processo. Pode-se utilizar de frases, ditados populares, gestos, fotografias, desenhos a mão, computador (CAD), bidimensionais (2D) ou tridimensionais (3D), maquete real, virtual e imagem mental, entre outras.

g) Ação - Encontrar conceitos para pesquisar - definir do ponto de vista dos serviços e funções do produto ou processo os conceitos para os eixos de pesquisa a serem tecnicamente desenvolvidos, específicos para o produto ou processo.

h) Ação - Representar as ideias a serem pesquisadas - definir, representar e materializar as ideias em conceitos de modo formal para se comunicar, para avaliação. Pode-se utilizar frases, ditados populares, gestos, fotografias, imagem mental, desenhos a mão, computador (CAD), bidimensionais (2D) ou tridimensionais (3D), maquete real, virtual e protótipo, entre outras.

i) Ação - Escolher as soluções para o produto ou processo - expressar de maneira genérica as soluções que atendem os serviços e funções esperados do produto ou processo e realizar a(s) escolha do(s) conceito(s) e ideias para essas soluções.

\section{EXPLICITAR (Meta-ação)}

j) Ação - Anotar dados particulares com detalhes e transformar em informações anotar dados particulares e seus detalhes para transformá-los em informações portadoras de sentido para as pessoas, de diferentes formas, através das ações anteriores.

k) Ação - Compreender e traduzir informações do produto ou processo - traduzir as informações obtidas para que se compreenda melhor o que se está propondo. Pode-se utilizar frases, ditados populares, gestos, fotografias, desenhos a mão, computador (CAD), bidimensionais (2D) ou tridimensionais (3D), maquete real, virtual e imagem mental, entre outras. 
l) Ação - Refletir as informações e as ideias para o produto ou processo - refletir, avaliar, expressar e memorizar de modo espontâneo as ideias das reflexões que surgem de forma aleatória ou simultaneamente das metas-ações e ações anteriores.

Esse MTF do processo criativo foi elaborado por Alberti (2006a) em função de um diagrama de afinidade (JIRO, 1991), sintetizando-se os resultados de uma pesquisa qualitativa em três grandes metas-ações. Por meio do desenvolvimento dessa pesquisa possibilitou-se identificar nos processos criativos as variáveis organizacionais (bases de dados pessoais ou por função, procedimentos dos diversos atores, hábitos de trabalhos, etc.) ferramentas, competências, ações, conhecimentos e comportamentos criativos.

Essas informações e suas variáveis foram agrupadas em grandes famílias, de forma arborescente, possibilitando-se identificar as especificidades de cada ação, tomando-se consciência da interdependência das metas-ações e dos fluxos aleatórios dessas iterações. Essas três metasações, nível mais geral do MTF, correspondem às três primeiras fases do mapa de posicionamento das ferramentas de auxílio à criatividade (VACARD, 1996).

No MTF a meta-ação Gerar apresenta-se como sendo uma fase que por muito tempo permaneceu como uma caixa preta, sendo estruturada de forma recente. A meta-ação Analisar apresenta-se como standard ou inicial, estimulando-se a tradução dos elementos e variáveis para o processo de criação (ALBERTI; DEJAN; CAYOL, 2006). No MTF, de forma distinta aos modelos de corpo teórico, não se sugestiona, "incubando" ou "iluminando" as fases, estimula-se as ações e suas interações formalizadas pelas setas, representa-se as repetições e confrontação das ideias para os ajustes, as hipóteses, os argumentos e a troca de conhecimento, proporcionando as iluminações.

Dessa forma o MTF possui características que possibilita e estimula o processo criativo nas empresas industriais, por meio da CF e CP, potencializando-se novas soluções para os problemas, combinando ideias e informações técnicas com a intuição criativa. Permite-se descrever o processo criativo nessas empresas de forma técnica, identificando os integrantes, ferramentas, competências, conhecimentos, métodos e os contextos das ações, para sua organização, documentação e análise.

\section{Resultados - Caso do processo de encartuchamento}

O processo produtivo analisado processa blisters de remédios (cartelas de comprimidos) para o seu encartuchamento (montagem nas caixa com as cartelas e a bula). A indústria onde se realizou o trabalho possui porte médio e atua no ramo farmacêutico, situando-se na região Metropolitana de Curitiba-PR. Por meio do gráfico de Pareto da qualidade identificaram-se os maiores índices de não conformidade do processo produtivo que necessitavam de retrabalho para se manter a qualidade desse processo produtivo. 
Essa necessidade de melhoria possibilitou a aplicação do MTF para uma proposta de solução, montando-se uma equipe multidisciplinar com integrantes do controle de qualidade, da tecnologia da informação, da produção e da engenharia. Esse projeto denominou-se OGIDE (Otimização e Garantia da Impressão dos Dados nas Embalagens) e possuía os seguintes índices iniciais do controle de qualidade :

Tabela 1 - Gráfico de Pareto com os índices das não conformidades do processo produtivo de 2006

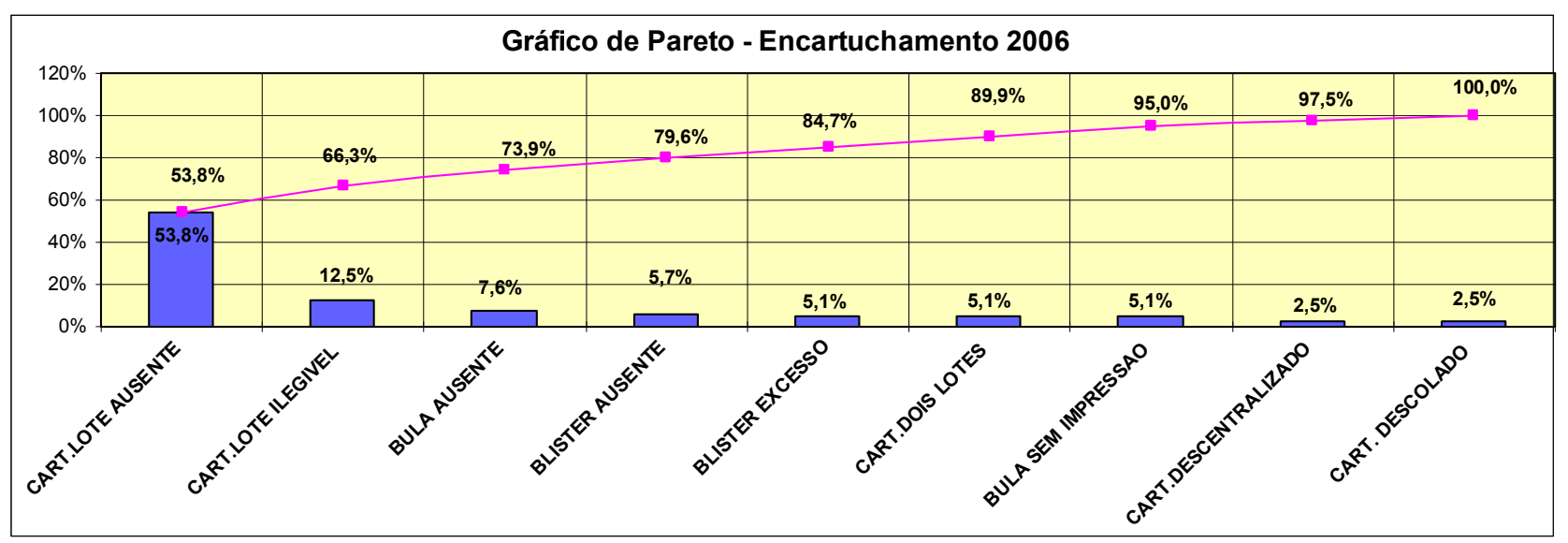

Fonte: Autor

Verifica-se que os dois maiores índices de problemas do Gráfico de Pareto eram relativos a impressão dos cartuchos e totalizavam $66,3 \%$ do total de não conformidades, dos $100 \%$ possíveis, sendo esses dois índices os principais problemas a serem melhorados ou eliminados com a aplicação do MTF. Para uma melhor interpretação dos dados desse projeto tornava-se necessário identificar detalhadamento o processo produtivo estudado, sendo que os dados foram coletados em função das ações do MTF planejadas pelo grupo OGIDE.

Portanto, o processo produtivo avaliado (figura 4) consistia em: o Colaborador A alimenta o Equipamento que faz os Blisters B1 (cartela) com os comprimidos e o Colaborador B realiza a inspeção dos blisters; na Esteira Transportadora E1 os Colaboradores C preparam os sub-lotes dos blisters; na Mesa M1 os Colaboradores D e E recolhem e inspecionam os sub-lotes dos blisters; na Esteira Transportadora E2 os colaboradores F e G montam os blisters com a bula nos cartuchos (caixas); no final da Esteira E2 a Impressora Loteadora LTD imprime os lotes e a validade nos Cartuchos; a Esteira Balança E3B pesa e descarta os cartuchos com problemas; nas Mesas M2 e M3 os Colaboradores $\mathrm{H}$ e I inspecionam os cartuchos produzidos; o Colaborador $\mathrm{J}$ alimenta manualmente a Esteira Lacradora E4L para a lacração; e finalmente nas Mesas M4 e M5 os Colaboradores K e L inspecionam, embalam e despacham os lotes em pallets para a expedição. 
Figura 5 - Layout atual (inicial) do processo de encartuchamento (caixas) dos blisters (comprimidos)

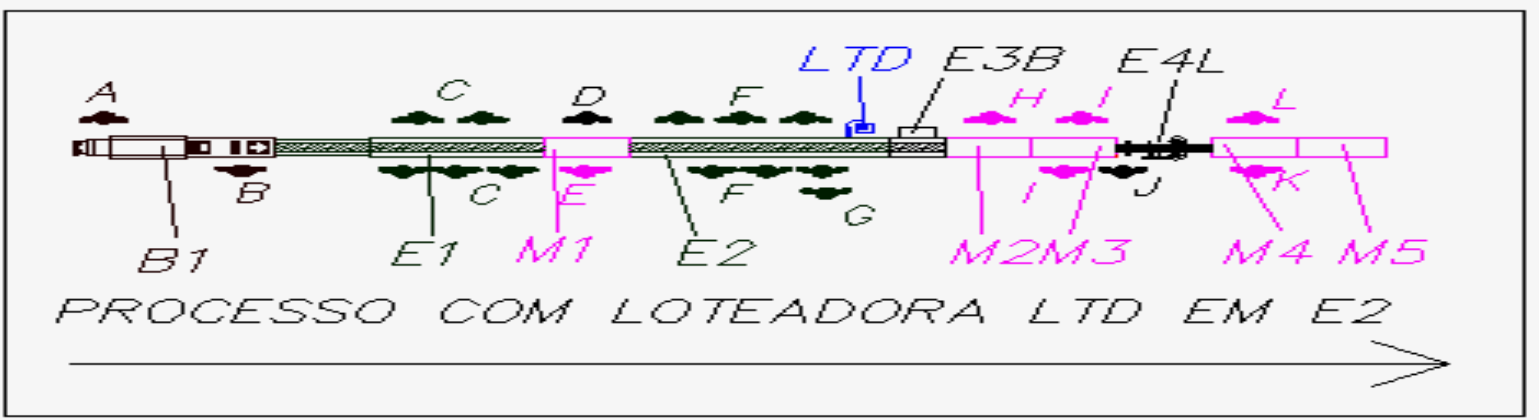

Fonte: Autor

$\mathrm{Na}$ avaliação dessa aplicação do MTF pesquisou-se as diversas etapas de trabalho do grupo OGIDE, os tipos de dados e informações, os métodos e as ferramentas utilizadas, confrontando-se as ações com o modelo do processo criativo. As ações desse processo foram sendo levantados e tabulados na sequência aleatória em que ocorreram as ações mais importantes, registrando-se de forma sequencial as mesmas, para estudo do caso, avaliação e análise dos resultados, como segue:

Quadro 1 - Confrontação do MTF e as ações executadas pelo OGIDE

\begin{tabular}{|c|c|c|c|c|}
\hline Ação & Modelo Trevo Fractal & Descrição & $\begin{array}{l}\text { Formato das } \\
\text { Informações }\end{array}$ & $\begin{array}{c}\text { Ferramentas } \\
\text { ou Métodos }\end{array}$ \\
\hline 1 & $\begin{array}{l}\text { Analisar as informações } \\
\text { sobre o produto ou } \\
\text { processo }\end{array}$ & $\begin{array}{l}\text {-Identificação do problema a ser melhorado: } \\
\text {-Obter a impressão em todos os cartuchos } \\
\text { (caixas) de forma legível. }\end{array}$ & $\begin{array}{c}\text { Gráficos de barras e } \\
\text { Verbal. }\end{array}$ & $\begin{array}{l}\text { Gráfico de } \\
\text { Pareto da } \\
\text { qualidade. }\end{array}$ \\
\hline 2 & $\begin{array}{l}\text { Identificar as formas de } \\
\text { utilização do produto ou } \\
\text { processo }\end{array}$ & $\begin{array}{l}\text {-Identificação da forma de impressão: } \\
\text {-Impressão contínua dos cartuchos sobre a } \\
\text { esteira transportadora E2. } \\
\text {-Análise de cartuchos impressos. }\end{array}$ & $\begin{array}{l}\text { Análise Visual, } \\
\text { Verbal e Croquis. }\end{array}$ & $\begin{array}{l}\text { Reunião do } \\
\text { Grupo. }\end{array}$ \\
\hline 3 & $\begin{array}{c}\text { Definir as } \\
\text { características do } \\
\text { processo produtivo }\end{array}$ & $\begin{array}{l}\text {-Principais Características do Processo: } \\
\text {-Na Esteira Transportadora E2 os } \\
\text { colaboradores F e G montam os blisters com } \\
\text { a bula nos cartuchos (figura 4). } \\
\text {-No fim da E2 a Impressora Loteadora LTD } \\
\text { imprime os lotes e a validade nos Cartuchos. } \\
\text {-Nas Mesas M2 e M3 os Colaboradores H e I } \\
\text { inspecionam os cartuchos completos. }\end{array}$ & $\begin{array}{c}\text { Desenhos 2D, } \\
\text { Verbal e Croquis }\end{array}$ & $\begin{array}{l}\text { Reunião do } \\
\text { Grupo, CAD e } \\
\text { Flip-chart. }\end{array}$ \\
\hline 4 & $\begin{array}{l}\text { Anotar dados } \\
\text { particulares com } \\
\text { detalhes e transformar } \\
\text { em informações }\end{array}$ & $\begin{array}{l}\text {-Visita à produção para se levantar dados: } \\
\text {-Dado 1: Na LTD o Sensor não reconhece os } \\
\text { cartuchos sem espaçamento na esteira. } \\
\text {-Dado 2: Na LTD Regula-se o sensor e a } \\
\text { cabeça da impressão para cartuchos diversos. }\end{array}$ & $\begin{array}{c}\text { Análise Visual e } \\
\text { Verbal. }\end{array}$ & $\begin{array}{l}\text { Visita ao } \\
\text { processo } \\
\text { produtivo. }\end{array}$ \\
\hline 5 & $\begin{array}{c}\text { Definir as } \\
\text { características do } \\
\text { processo produtivo }\end{array}$ & $\begin{array}{l}\text {-Identificação das características e funções do } \\
\text { processo que interferem nos índices: } \\
\text {-Função 1: A utilização da esteira não } \\
\text { permite que os cartuchos sejam impressos } \\
\text { corretamente. } \\
\text {-Função 2: A Impressora não possibilita a } \\
\text { impressão em cartuchos sem espaços entre si. }\end{array}$ & $\begin{array}{l}\text { Verbal e Desenhos } \\
\text { 2D. }\end{array}$ & $\begin{array}{l}\text { Análise } \\
\text { Funcional e } \\
\text { Flip-chart. }\end{array}$ \\
\hline 6 & $\begin{array}{l}\text { Refletir as informações } \\
\text { e as ideias para o } \\
\text { produto ou processo }\end{array}$ & $\begin{array}{l}\text {-Discussão e reflexão das informações pelo } \\
\text { grupo, para a maturação das ideias e das } \\
\text { próximas ações. }\end{array}$ & Croquis e Verbal. & $\begin{array}{l}\text { Reunião do } \\
\text { grupo e Flip- } \\
\text { chart. }\end{array}$ \\
\hline
\end{tabular}




\begin{tabular}{|c|c|c|c|c|}
\hline 7 & $\begin{array}{l}\text { Encontrar conceitos } \\
\text { para pesquisar }\end{array}$ & $\begin{array}{l}\text {-Conceito de Pesquisa 1: Sistema de } \\
\text { separação mecânica para impressão da LTD } \\
\text { (baseado na Função 1). } \\
\text {-Conceito de Pesquisa 2: Impressora permite } \\
\text { a impressão sem espaços entre os cartuchos } \\
\text { (baseado na Função 2). }\end{array}$ & $\begin{array}{l}\text { Análise Visual, } \\
\text { Verbal, Croquis e } \\
\text { Desenhos 2D. }\end{array}$ & $\begin{array}{l}\text { Análise } \\
\text { Funcional e } \\
\text { Flip-chart. }\end{array}$ \\
\hline 8 & $\begin{array}{l}\text { Levantar as tendências } \\
\text { do produto ou processo }\end{array}$ & $\begin{array}{l}\text {-Visita a uma fábrica de cabos de fibra ótica } \\
\text { que possui impressão sequencial dos cabos. }\end{array}$ & $\begin{array}{l}\text { Análise Visual e } \\
\text { Verbal. }\end{array}$ & Benchmarking. \\
\hline 9 & $\begin{array}{l}\text { Representar as ideias a } \\
\text { serem pesquisadas }\end{array}$ & $\begin{array}{l}\text {-Ideia 1 / Solução 1: Utilização de rampa, } \\
\text { defletor, espaçador na esteira ou outros } \\
\text { princípios mecânicos (baseado no Conceito } \\
\text { 1). } \\
\text {-Ideia } 2 \text { / Solução 2: Mudança dos sensores, } \\
\text { alteração da lógica dos mesmos ou nova } \\
\text { impressora (baseado no Conceito 2). } \\
\text {-Realização de testes rápidos, de forma } \\
\text { prática, com diversos dispositivos defletores } \\
\text { no processo produtivo, sem bons resultados. }\end{array}$ & $\begin{array}{l}\text { Verbal, Desenhos } \\
\text { 2D e 3D, Protótipo } \\
\text { e Análise Visual. }\end{array}$ & $\begin{array}{l}\text { Reunião do } \\
\text { grupo, CAD e } \\
\text { Flip-chart. }\end{array}$ \\
\hline 10 & $\begin{array}{l}\text { Avaliar o ambiente e a } \\
\text { utilização do produto ou } \\
\text { processo }\end{array}$ & $\begin{array}{l}\text {-Reunião com os responsáveis pela } \\
\text { manutenção dos equipamentos do processo: } \\
\text {-Dado 3: A manutenção já tinha testado } \\
\text { outros sensores para a LTD, considerando-se } \\
\text { os atuais como sendo os melhores para o } \\
\text { processo. } \\
\text {-Dado 4: Tinham sido testados separadores } \\
\text { mecânicos sem sucesso pela manutenção. } \\
\text {-Dado 5: Para a manutenção a única } \\
\text { separação mecânica possível seria por } \\
\text { diferença de velocidades entre as esteiras. }\end{array}$ & Verbal e Croquis. & $\begin{array}{l}\text { Reunião do } \\
\text { Grupo com } \\
\text { participantes do } \\
\text { ambiente. }\end{array}$ \\
\hline 11 & $\begin{array}{l}\text { Levantar as tendências } \\
\text { do produto ou processo }\end{array}$ & $\begin{array}{l}\text {-Reunião com os responsáveis pela } \\
\text { manutenção dos equipamentos do processo: } \\
\text {-Dado 6: A manutenção apresentou dados } \\
\text { sobre modelos de impressoras que atendiam } \\
\text { ao processo sem alterações. } \\
\text {-Dado 7: Avaliaram-se os custos dessas } \\
\text { impressoras, apresentando-se inviáveis. }\end{array}$ & Verbal. & $\begin{array}{l}\text { Reunião do } \\
\text { Grupo com } \\
\text { participantes do } \\
\text { ambiente }\end{array}$ \\
\hline 12 & $\begin{array}{l}\text { Avaliar o ambiente e a } \\
\text { utilização do produto ou } \\
\text { processo }\end{array}$ & $\begin{array}{l}\text { O pessoal da manutenção funcionava como } \\
\text { inibidor da criatividade. Segundo a } \\
\text { manutenção não havia solução através de } \\
\text { ideias para os Conceitos de Pesquisa } 1 \text { e } 2 \text {. }\end{array}$ & Verbal. & $\begin{array}{l}\text { Reunião do } \\
\text { Grupo. }\end{array}$ \\
\hline 13 & $\begin{array}{l}\text { Refletir as informações } \\
\text { e as ideias para o } \\
\text { produto ou processo }\end{array}$ & $\begin{array}{l}\text {-Insistir nas Ideias / Soluções } 1 \text { ou } 2 \text { poderia } \\
\text { criar conflito com a manutenção, pois } \\
\text { apresentavam alto risco de insucesso e já se } \\
\text { tinham sido realizados pré-testes pelo grupo. }\end{array}$ & Verbal. & $\begin{array}{l}\text { Reunião do } \\
\text { Grupo. }\end{array}$ \\
\hline 14 & $\begin{array}{l}\text { Encontrar conceitos } \\
\text { para pesquisar }\end{array}$ & $\begin{array}{l}\text {-Conceito de Pesquisa 3: Separação } \\
\text { mecânica (baseado na Função 1). }\end{array}$ & Verbal. & $\begin{array}{l}\text { Reunião do } \\
\text { Grupo. }\end{array}$ \\
\hline 15 & $\begin{array}{l}\text { Compreender e traduzir } \\
\text { informações do produto } \\
\text { ou processo }\end{array}$ & $\begin{array}{l}\text {-Análise do layout e das esteiras do processo } \\
\text { com possibilidades de separação mecânica } \\
\text { dos cartuchos para a impressão. }\end{array}$ & Desenho 2D e 3D. & $\begin{array}{l}\text { CAD, Datashow } \\
\text { e Flip-chart. }\end{array}$ \\
\hline 16 & $\begin{array}{l}\text { Representar as ideias a } \\
\text { serem pesquisadas }\end{array}$ & $\begin{array}{l}\text {-Ideia 3 / Solução 3: Mudar Impressora LTD } \\
\text { da Esteira E2 para a Esteira da balança E3B. } \\
\text {-Ideia / Solução 4: Aquisição de uma nova } \\
\text { esteira intermediária para a Impressora LTD. }\end{array}$ & Desenho 2D e 3D. & $\begin{array}{l}\text { CAD, Datashow } \\
\text { e Flip-chart. }\end{array}$ \\
\hline 17 & $\begin{array}{l}\text { Refletir as informações } \\
\text { e as ideias para o } \\
\text { produto ou processo }\end{array}$ & $\begin{array}{l}\text {-A implantação da Ideias / Soluções } 3 \text { ou } 4 \\
\text { implicavam em aquisição de novos } \\
\text { equipamentos auxiliares e investimentos. }\end{array}$ & Desenho 2D e 3D. & $\begin{array}{l}\text { Reunião do } \\
\text { Grupo e Flip- } \\
\text { chart. }\end{array}$ \\
\hline 18 & $\begin{array}{l}\text { Investigar as funções } \\
\text { (novas e tradicionais) do } \\
\text { produto ou processo }\end{array}$ & $\begin{array}{l}\text {-Visita ao processo produtivo para análise: } \\
\text {-Identificação no processo produtivo que a } \\
\text { Esteira Lacradora E4L possuía função de } \\
\text { separação dos cartuchos para a lacração. }\end{array}$ & Verbal e visual. & $\begin{array}{l}\text { Visita ao } \\
\text { processo } \\
\text { produtivo. }\end{array}$ \\
\hline 19 & $\begin{array}{l}\text { Representar as ideias a } \\
\text { serem pesquisadas. }\end{array}$ & $\begin{array}{l}\text {-Ideia 5 / Solução 5: Mudar a Impressora } \\
\text { LTD para a Esteira Lacradora E4L, } \\
\text { readequando-se os equipamentos, os } \\
\text { controles e as funções dos colaboradores para } \\
\text { o novo layout (baseado no conceito 3). }\end{array}$ & Verbal. & $\begin{array}{l}\text { Reunião do } \\
\text { Grupo. }\end{array}$ \\
\hline
\end{tabular}




\begin{tabular}{|c|c|c|c|c|}
\hline 20 & $\begin{array}{c}\text { Anotar dados } \\
\text { particulares com } \\
\text { detalhes e transformar } \\
\text { em informações }\end{array}$ & $\begin{array}{l}\text {-Visita ao processo produtivo para análise: } \\
\text { - Necessidade de alteração dos controles de } \\
\text { qualidade e alteração das funções, mas sem } \\
\text { aquisição ou alterações nos equipamentos. }\end{array}$ & Verbal e visual. & $\begin{array}{l}\text { Visita ao } \\
\text { processo } \\
\text { produtivo. }\end{array}$ \\
\hline 21 & $\begin{array}{l}\text { Avaliar o ambiente e a } \\
\text { utilização do produto ou } \\
\text { processo }\end{array}$ & $\begin{array}{l}\text {-A princípio o responsável pelo controle da } \\
\text { qualidade que fazia parte do OGIDE ficou } \\
\text { temeroso com as alterações dos controles. }\end{array}$ & Verbal. & $\begin{array}{l}\text { Reunião do } \\
\text { Grupo. }\end{array}$ \\
\hline 22 & $\begin{array}{l}\text { Representar as ideias a } \\
\text { serem pesquisadas }\end{array}$ & $\begin{array}{l}\text {-Planejamento e teste do Conceito } 3 \text { com as } \\
\text { definições da Ideia } 5 \text { / Solução no processo } \\
\text { produtivo, para análise e estudo da solução. } \\
\text {-Responsável pelo Controle da Qualidade } \\
\text { aceitou as alterações planejadas para teste. }\end{array}$ & $\begin{array}{l}\text { Verbal, Desenhos } \\
\text { 2D, Protótipo e } \\
\text { Análise Visual. }\end{array}$ & $\begin{array}{l}\text { CAD, Flip-chart } \\
\text { e Visita ao } \\
\text { processo } \\
\text { produtivo. }\end{array}$ \\
\hline 23 & $\begin{array}{l}\text { Escolher as soluções } \\
\text { para o produto ou } \\
\text { processo }\end{array}$ & $\begin{array}{l}\text {-Análise dos resultados dos testes (Gráfico de } \\
\text { Pareto) e verificação da viabilidade de da } \\
\text { solução, atendendo-se as normas. } \\
\text {-Escolha da Ideia / Solução } 5 \text { como solução } \\
\text { ideal. }\end{array}$ & $\begin{array}{c}\text { Gráficos de barras e } \\
\text { Verbal. }\end{array}$ & $\begin{array}{l}\text { Gráfico de } \\
\text { Pareto da } \\
\text { qualidade. }\end{array}$ \\
\hline
\end{tabular}

Fonte: autor

Com o mapeamento do processo produtivo decompôs-se o todo em partes, para análise minuciosa dessas partes e suas atividades, identificando-se as funções, características e suas relações, para a realização da Análise Funcional.

Por meio dessa análise identificou-se que, para funcionar adequadamente o processo de impressão os cartuchos deveriam estar separados na esteira E2, gerando a correta identificação e impressão dos mesmos pela Loteadora LTD.

No entanto, os Colaboradores $\mathrm{C}$ apesar de orientados a realizar a separação desses cartuchos na esteira E2 nem sempre obtinham sucesso, o que se deve a grande velocidade e fluxo contínuo da produção, gerando-se falhas nesse processo.

Dessa forma realizaram-se reuniões com o grupo OGIDE para discussão dos problemas e das possíveis alternativas de soluções. Sendo que, após modelamento do processo produtivo pelo grupo OGIDE e análises preliminares das ideias destacaram-se as seguintes propostas de soluções para a melhoria desse processo:

- Solução 1: Defletor mecânico com mola para retenção e separação sincronizada.

- Solução 2: Mudança dos sensores, alteração da lógica dos mesmos ou nova impressora.

- Solução 3: Mudar Impressora LTD da Esteira E2 para a Esteira da balança E3B.

- Solução 4: Aquisição de uma nova esteira intermediária com velocidade superior a da Esteira E2.

- Solução 5: Reinstalação da Loteadora impressora LTD na esteira lacradora E4L, incluindo readequação do processo produtivo e seus controles.

No entanto, para decisão do conceito e da solução a ser utilizada se tornou necessário uma análise mais profunda, antes da tomada de decisão final, pois todos as soluções possuiam vantagens e desvantagens. Dentre as vantagens e desvantagens de cada solução destacam-se: solução 1 não 
gerava confiabilidade no funcionamento do dispositivo pois precisava ser desenvolvida; solução 2 requeria alto investimento em automação ou aquisição de nova impressora; solução 3 não seria viável em função do tamanho reduzido da esteira balança e da dificuldade de se montar em conjunto com o sistema de pesagem; solução 4 necessitava da aquisição de um novo equipamento com alto investimento; solução 5 necessitava somente de alteraração do layout da produção com readequação das funções dos colaboradores e os controles da qualidade, sem investimentos em equipamentos.

\section{Discussões dos resultados}

Para a implantação da solução 5 com base no conceito 3 precisava se readequar os controles de qualidade segundo a norma ISO 9000: 2000, realizando-se uma revisão das operações dos colaboradores, para se atender a norma e aperfeiçoar o novo layout produtivo. Sendo que esse plano de solução possuía baixo risco de implantação e não necessitava de investimentos em equipamentos para a realização de um teste preliminar. Dessa forma desenvolveu-se a ideia que utilizava o conceito 3, solução essa gerada na Ação 19 por meio da Ideia 5: Mudar a Impressora Loteadora LTD da Esteira E2 para a Esteira Lacradora E4L, após a lacração, a qual utiliza separação mecânica manual das caixas, como segue:

Figura 6 - Proposta de melhoria do layout produtivo do encartuchamento

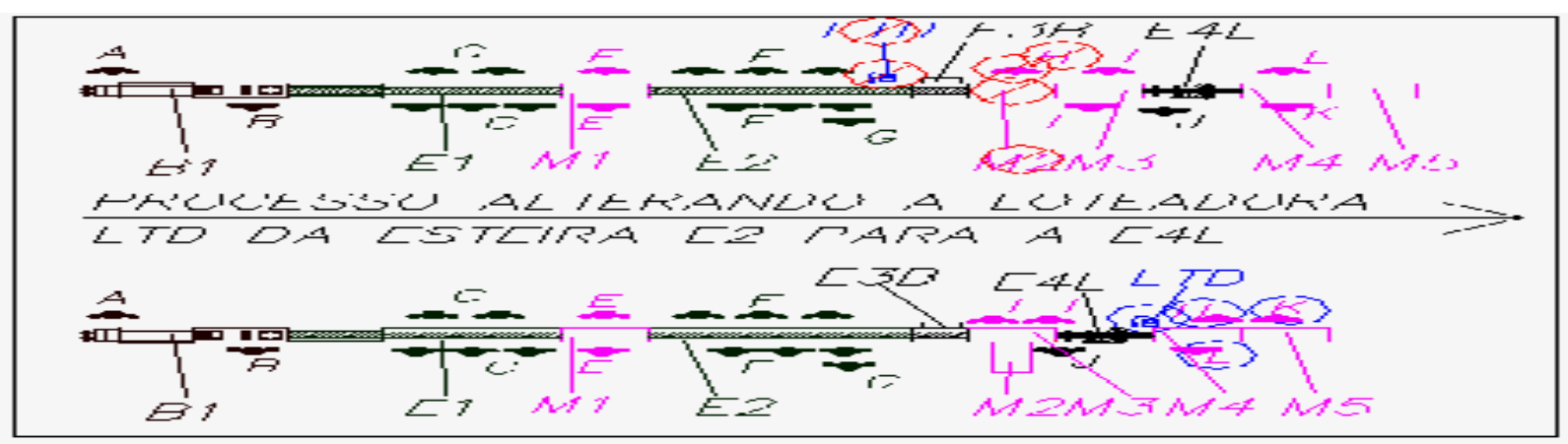

Fonte: Autor

Inicialmente foram realizados testes durante um dia, que em função dos resultados satisfatórios foram estendidos para uma semana e, posteriormente, para um mês. Realizados um mês de produção com significativa melhoria dos resultados obtidos no gráfico de Pareto definiu-se que os testes se estenderiam por mais 2 meses, totalizando 3 meses de testes, para a implantação definitiva.

Realizados os três meses de testes, no período de Janeiro a Março de 2007, com a implantação provisória da solução obteve-se novos índices para os problemas identificados anteriormente: 
Tabela 2 - Melhoria dos índices de retrabalho com a solução do MTF

\begin{tabular}{cccc}
\hline Não Conformidade & $\begin{array}{c}\text { Índice Inicial } \\
\text { (Janeiro a Dezembro/2007) }\end{array}$ & $\begin{array}{c}\text { Índice Final } \\
\text { (Janeiro a Março/2007) }\end{array}$ & $\begin{array}{c}\text { Redução Total } \\
\text { por Î́ndices }\end{array}$ \\
\hline Cartucho com Lote Ausente & $53,8 \%$ & $0 \%$ & $53,8 \%$ \\
Cartucho com Lote Ilegível & $12,5 \%$ & $0,5 \%$ & $12, \%$ \\
Demais itens não conformes & $33,7 \%$ & $99,5 \%$ & ----- \\
Total & $100 \%$ & $100 \%$ & $65,8 \%$ \\
\hline
\end{tabular}

Fonte: Autor

A solução aplicada ao processo produtivo a partir da Ideia 5 / Solução 5 criada no MTF apresentou resultados práticos adequados, pois a queda no índice de retrabalho produtivo devido aos índices de impressão total foi de $65,8 \%$.

No entanto, a diminuição do índice de Cartucho com Lote Ausente era esperada, constatado com a sua eliminação, mas a diminuição do índice Cartucho com Lote Ilegível de $12,5 \%$ para $0,5 \%$ não era esperado.

Com a nova posição da Impressora LTD no layout também evitou-se falhas operacionais não identificadas inicialmente, pois esperava-se que a maior parte do índice Cartucho com Lote Ilegível fosse devido a falhas de limpeza e manutenção diária LTD, a qual não passou por melhoria.

Para a implantação dessa solução de melhoria e mudança no layout produtivo realizaram-se treinamentos com os colaboradores para a execução das novas operações e aprendizado dos novos tipos de registros dos dados para controle da qualidade. Realizado o primeiro teste produtivo (figura7) os colaboradores não queriam o retorno ao processo produtivo antigo, pois o novo processo tornou-se mais simples, facilitando-se a comunicação entre os mesmos.

Figura 7 - Separação mecânica (1) na esteira lacradora E4L e impressora loteadora LTD (2) com o sensor (3)
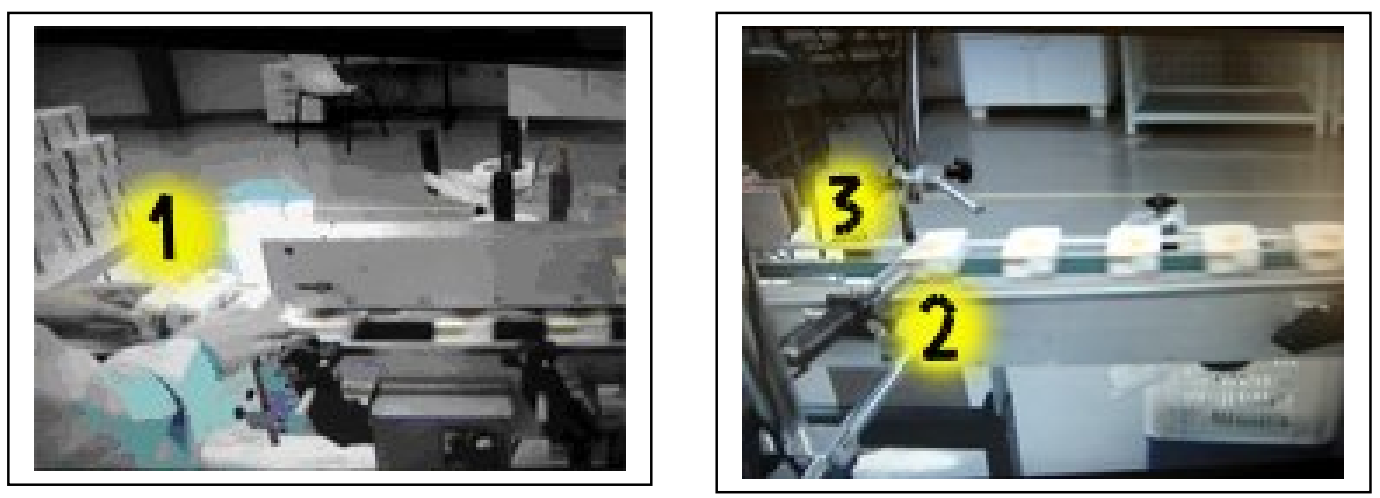

Fonte: Autor

Na aplicação do MTF a Análise de Valor teve papel fundamental, confirmando Miles (1972), Abramczuk (1991) e Basso (1991), através de seu enfoque criativo e organizado da Análise 
Funcional (ligada ao desempenho). Na ação 5 Definir as características do processo produtivo inicia-se a reflexão do processo produtivo, que contribui com a criação dos Conceitos de Pesquisa 1,2 e 3. Observa-se que o Conceito 3 potencializa-se a Ideia 5 / Solução 5 (mudar a impressora oteadora LTD da esteira E2 para a esteira lacradora E4L) a qual se fundamenta na melhoria da Função 1 da Análise Funcional (a esteira não permite que os cartuchos sejam impressos corretamente), melhorando-se as operações e os controles de qualidade.

Dessa forma, nas ações 18, 19 e 20, tal como afirmou Alencar (1996) percebe-se também a criatividade associada aos processos de pensamentos estimulados pelo MTF, potencializando-se uma nova ideia nessas ações, com viabilidade de aplicação prática, tornando-se a Ideia 5 / Solução 5 a ideia original para a solução definitiva. A aplicação dessa ideia apóia os conceitos de Kanter, Kao e Wiersema (1998), pois se possibilita a aplicação prática da ideia no processo, eliminando os custos de retrabalho gerados pela impressão inadequada.

Dessa forma concorda-se com Savolainen (1999), pois não existe uma única e melhor maneira para se realizar uma melhoria de processo produtivo, pois existem comportamentos específicos em cada organização que alimentam a pesquisa de novas ideias e soluções.

Também Alencar (1996) relata esses tipos de comportamentos específicos influenciando a evolução dos processos produtivos, por meio de soluções rápidas que exigem criatividade dos colaboradores, o que impossibilita o estabelecimento de regras prévias.

Percebe-se na aplicação do MTF estudado que o comportamento específico do ambiente das ações 12 e 21 (Avaliar o ambiente e a utilização do produto ou processo) contribuem e influenciam a solução final, de forma positiva ou negativa, impossibilitando realmente o estabelecimento de regras e soluções orientadas.

Verifica-se que o processo criativo por meio do MTF apresenta características que estimulam a criação das soluções e a busca por melhores resultados, respeitando o contexto organizacional, sem a imposição de regras e caminhos prévios para essas soluções.

Observa-se que as ações do processo criativo, por meio de caminhos aleatórios e sem ferramentas específicas limitantes fornecem liberdade de criação aos colaboradores, possibilitandose diversas soluções.

\section{Considerações finais}

$\mathrm{Na}$ busca de soluções por meio do processo criativo pelo Modelo Trevo Fractal verifica-se o estimulo ao desenvolvimento de novas maneiras de se fazer mais com menos, potencializando-se a redução de custos e a simplificação de processos, para novas utilizações dos produtos e processos. 
Dessa forma o Modelo Trevo Fractal mostrou-se um modelo de aplicação viável industrialmente, contribuindo para a solução do processo analisado, apresentando resultados práticos significativos, eliminando-se mais da metade dos custos de retrabalho da produção identificados como problema.

Apesar da aleatoriedade do modelo do processo criativo Trevo Fractal obteve-se suporte descritivo das ações desse processo que foram organizadas no tempo, mesmo sendo aleatoriamente, mas com resultados mensuráveis após a ocorrência de cada uma.

Essa vantagem do modelo se mostrou como uma de suas qualidades fundamentais, aproximando-se a subjetividade do processo criativo da necessidade industrial de organização desses processos nas empresas.

O modelo do processo criativo avaliado também possibilitou a utilização da Criatividade Funcional por meio de suas ações e da ferramenta Análise Funcional. Sendo que, no modelo a Criatividade Parametrizada por meio da utilização dos parâmetros organizacionais das empresas e seu contexto tecnológico se mostrou fundamental para a geração da ideia de solução, pois a ação “avaliar o ambiente e a utilização do produto ou processo" estimulou a solução final.

No entanto, a maior dificuldade na utilização desse modelo encontrada pela equipe OGIDE pode parecer um contra-senso, mas foi justamente a falta de procedimentos sequenciais, possibilitando-se vários caminhos e soluções.

A ausência desse tipo de orientação prévia na utilização das ferramentas e ações prédeterminadas ou orientadas aproxima esse modelo a um processo de pesquisa científico, onde a sequência e as ações são determinadas caso a caso.

$\mathrm{Na}$ formulação do problema e a sua resolução verifica-se também a importância da utilização de ferramentas específicas, tal como a Análise Funcional, estímulando-se a interação das ações incrementais e evolutivas das ideias, mas de forma mensurável pelo Modelo Trevo Fractal.

Este trabalho investigou a aplicação do modelo do processo criativo Trevo Fractal no processo produtivo de uma indústria farmacêutica, verificando-se a viabilidade de melhoria desse processo, por meio da geração e implantação de uma ideia criativa como solução.

Porém, por se tratar de um estudo de caso necessita-se de mais trabalhos em outros processos produtivos e novos ramos, para se verificar por meio do modelo o desenvolvimento de soluções para outros produtos. 


\begin{abstract}
In the improvement of productive processes, it is common to utilize tools, techniques or creativity methods, mostly sequential, like pre-defined ways to generate ideas, concepts and solutions with innovative potential, against purely technical ideas. However, these kinds of models and tools limit the creative process, as well as its randomness and temporality. In the search for creative solutions that don't occur only by chance, but contemplate the analysis of stimulator variables of a creative process, as well as its process of creation in an extemporal and random form, it was fulfilled a case study with the model of Fractal Clover Creativity. In this work, it was contemplated the elimination or the minimization of quality problems of the productive process of a medium size industry, which acts in the pharmaceutical field in the metropolitan area of Curitiba. It has been tried to establish the scanning of the company and its variables, through its description, identifying competences, knowledge and tools to the fulfillment of actions, in the search for ideas, concepts and a creative solution. A solution developed through the Fractal Clover Creativity Model, after being implanted, presented as a result, the elimination of the main problem $(53,8 \%$ from the total) and the minimization of the second problem (from $12,5 \%$ to $0,5 \%$ ) of non conformities in the productive process. The necessary time for the development and the solution creation, as well as for its implantation was three months, generating an improvement of the process, with no need of investments, alteration or equipment acquisition.
\end{abstract}

Key-words: improvement of the production process, model of the creative process, creative solutions.

\title{
Referências
}

ABRAMCZUK, A. A. Para que serve a análise de valor? Para que poderia servir? In: Valor em Perspectiva, ABREAV, p. 15-20, Florianópolis, 1991.

ALBERTI, P. Formação de consultores para a inovação na indústria. Curitiba: Unindus, $2006 a$.

ALBERTI, P. Stimuler la criatividade par la mise à disposition de la connaisance capitalisée. Paris, 2006. Thèse, (Doctorat em Génie Industriel) - Ecole Centrale Paris, Paris, 2006b.

ALBERTI, P.; DEJAN, P. H.; CAYOL A. The organisation of an innovation project assisted by a creativity model. International Design Conference - Design 2006. Proceedings... Dubrovnik - Croatia, May 15 - 18, 2006.

ALENCAR, E. M. L. S. A gerência da criatividade. São Paulo: Makron Books, 1996.

ALTSHULLER, G. S. Creativity as an exact science: the theory of the solution of inventive problems. Luxemburg: Gordon \& Breach, 1984.

ASSOCIAÇÃO BRASILEIRA DE NORMAS TÉCNICAS. NBR ISO 9000:2000 - Sistema de gestão da qualidade: requisitos. $A B N T$ : Rio de Janeiro, 2000.

BACK, N. Metodologia de projeto de produtos industriais. Rio de Janeiro: Guanabara Dois, 1983.

BASSO, J. L. Engenharia de valor. São Paulo: IMAN, 1991.

BAXTER, M. Projeto de produto: guia para o desenvolvimento de novos produtos. São Paulo: Edgard Blüncher, 1998.

BRENNAN, A.; DOOLEY, L. Networked creativity: a structured management framework for stimulating innovation. Technovation, v. 25, n. 12, p. 1388-1399, dec. 2005.

cross ref

BUZAN, T. The mind map book. New York: Penguin Books, 1991.

CAMPBELL, D. T. Blind variation and selective retention in creative thought as in other knowledge processes. Psychological Review, Vol. 67, p. 380-400, 1960.

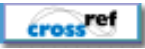

DE BONO, E. New think: the use of lateral thinking in the generation of new ideas. New York: Basic Books, 1968. 
EVBUOMWAN, N. F.; SIVAlOGANATHAN, S.; JEBB, J. A Survey of design philosophies, models, methods and systems. Journal of Engineering Manufacture, v. 210, n. 4, p. 301-320, 1996.

cross'

GORDON, W. J. J. Synectics. New York: Harper \& Row, 1961.

HELLFRITZ, H. Innovation via galeriemethode. Königstein/Ts: Eigenverlag, 1978.

JIRO, K. The original KJ Method. Tóquio: Kawakita Research Institute, 1991.

KANTER, R.; KAO, J.; WIERSEMA, F. Inovação: pensamento inovador na 3M, DuPont, GE, Pfizer e Rubbermaid. São Paulo: Negócio, 1998.

MILES, L. D. Techniques of value analysis and engineering. New York: McGraw-Hill, 1972.

OSBORN, A. F. Applied imagination. New York: Charles Scribner's Sons, 1953.

PARNES, S. J. Source book for creative problem solving. New York: Creative Education Press, 1992.

PLSEK, P. E. Creativity, innovation, and quality. Milwaukee: Quality Press, 1997.

PRINCE, G. M. The practice of creativity. New York: Collier Books, 1972.

ROHRBACH, B. Kreativ nach regeln: methode 635, eine neue technik zum lösen von problemen. Absatzwitschaft, Vol. 12, p. 73-75, 1969.

ROSSMAN, J. The psychology of the inventor: a study of the patentee. Whashington: Inventor's Publising, 1931.

ROZENFELD, H.; AMARAL, D.C.; FORCELlinI, F. A.; TOLEDO, J. C.; SILVA, S. L.; ALLIPRANDINI, D. H.; SCALICE, R. K. Gestão de desenvolvimento de produtos: uma referência para a melhoria do processo. São Paulo: Saraiva, 2006.

SAVOLAINEN, T. I. Cycles of continuous improvement: realizing competitive advantages through quality. International Journal of Operations \& Production Management, Vol. 19, n.11, p.1203-1222, 1999.

cross $^{\text {ref }}$

SIMONTON, D. K. Creativity, leadership, and chance. In: STERNBERG, R. J. The Nature of Creativity. Cambridge: Cambridge University Press, 1988.

TREFFINGER, D. J; ISAKSEN, S. G.; DORVAL, K. B. Creative problem solving: an introduction. Sarasota: Center for Creative Learning, 1994.

VACARD, P. Aide à la programmation del'utilisation des outils en conception de produit. Paris, 1996. Thèse (Doctorat en Génie Industriel) - Ecole Nationale Supérieure d'Arts et Metiers, Paris, 1996.

WALLAS, G. The art of thought. Nova York: Harcourt, 1926.

YIN, R. K. Estudo de caso: planejamento e métodos. Porto Alegre: Bookman, 2005.

ZWICKY, F. The morphological method of analysis and construction. New York: Wiley Interscience, 1948.

\section{Dados dos autores:}

Nome completo: Alexandre de Castro Alves

Filiação institucional: Universidade Tecnológica Federal do Paraná, Campus Ponta Grossa (PR)

Departamento: Coordenação de Mecânica

Função ou cargo ocupado: Professor do Magistério Superior

Endereço completo para correspondência: Avenida Monteiro Lobato, Km 04 - Jardim Pitangui - 
Ponta Grossa (PR) - Brasil

Coordenação de Mecânica - Cep: 84.016-210

Telefones para contato: 4232204828 - 4230288208 - 4299338208

e-mail:alexandrealves@utfpr.edu.br

Nome completo: Aldo Braghini Júnior

Filiação institucional: Universidade Tecnológica Federal do Paraná, Campus Ponta Grossa (PR)

Departamento: Coordenação de Mecânica

Função ou cargo ocupado: Professor do Magistério Superior

Endereço completo para correspondência: Avenida Monteiro Lobato, Km 04 - Jardim Pitangui -

Ponta Grossa (PR) - Brasil

Coordenação de Mecânica - Cep: 84.016-210

Telefones para contato: 4232204828 - 4232204853 - 4288067620

e-mail:aldo@utfpr.edu.br 